\title{
LONGSOR MERATA (TEKNOLOGI SENSOR KAMERA SEBAGAI KACAMATA PENGENAL TEKS UNTUK TUNA NETRA)
}

Achmad Hudah, Nurul Huda, Aditya Rizki Fauzi

${ }^{1,2,3}$ S1 Rekayasa Sistem Komputer, Fakultas Ilmu Komputer, Perguruan Tinggi STMIK ASIA MALANG

Email: ${ }^{[1]}$ hudah.asia@gmail.com, ${ }^{[2]}$ hudan3347@gmail.com, ${ }^{[3]}$ adityarizkifauzi@gmail.com

\begin{abstract}
ABSTRAK-Longsor merata (Teknologi Sensor Kamera Sebagai Kacamata Pengenal Teks Untuk Tuna Netra) adalah salah satu alat yang dibuat untuk penyandang tunanetra sebagai salah satu alternative minimnya media baca tunanetra khususnya buku cetak braille. Untuk memperoleh informasi dan menambah keilmuan seorang penyandang Tunanetra tidak lagi bergantung pada buku cetak braille. Dengan alat ini penyandang Tunanetra dapat membaca buku konvensional yang dibaca manusia normal pada umumnya. Teknik pengujian dalam penelitian ini menggunakan teknik pengujian Blackbox. Alat ini berhasil dibangun dengan Raspberry Pi sebagai mikrokontroller, dengan trigger dari Push Button sebuah Raspberry Pi Camera akan melakukan graphical capture dan menghasilkan sebuah file gambar yang secara otomatis akan diolah dengan proses Optical Character Recognition (OCR) dan dikonversi menjadi ucapan/speech dengan proses Text to Speech (TTS). Hasil dari rentetan proses ini menghasilkan sebuah file mp3 untuk diperdengarkan kepada penyandang tunanetra melalui pengeras suara/speaker sehingga penyandang tunanetra dapat membaca secara tidak langsung dari tulisan cetak dari sebuah kertas/halaman buku.
\end{abstract}

Kata kunci : Raspberry pi, Camera; Optical Character Recognition (OCR), Text To Speech(TTS), Tunanetra

ABSTRACT_Evenly landslide (Camera Sensor Technology as Identifying Glasses for Blind Text) is one of the tools made for blind people as one of the alternatives to the lack of reading media for blind people, especially braille print books. To obtain information and add to the knowledge of a blind person no longer depends on a braille print book. With this tool blind people can read conventional books that are read by normal humans in general. The testing technique in this study used the Blackbox testing technique. This tool was successfully built with the Raspberry Pi as a microcontroller, with a trigger from the Push Button a Raspberry Pi Camera will do graphical capture and produce an image file that will automatically be processed with the Optical Character Recognition (OCR) process and converted into speech / Text process to Speech (TTS). The results of this series of processes produce an mp3 file to be heard to blind people through loudspeakers / speakers so that blind people can read indirectly from printed writing from a paper / page book.

Index Terms: Raspberry pi, Camera; Optical Character Recognition (OCR), Text To Speech (TTS), blind 


\section{PENDAhULUAN}

Orang yang mengalami gangguan penglihatan mengeluhkan kesulitan dalam mengakses teks termasuk masalah penyelarasan, fokus, akurasi, mobilitas dan efisiensi kami membuat perangkat pintar yang membantu tunanetra yang secara efektif dan secara efisien membaca teks. Proyek yang diusulkan menggunakan metodologi alat bantu berbasis kamera yang dapat digunakan untuk membaca Teks dokumen. Kerangka kerjanya adalah mengimplementasikan pengambilan gambar teknik dalam embedded system berdasarkan Rasberry pi.

Dalam penelitian ini kami telah mengusulkan sistem pembacaan teks untuk orang yang mengalami gangguan secara visual. Sistem terintegrasi yang diusulkan memiliki kamera sebagai perangkat input untuk memindai dokumen teks cetak untuk digitasi dan dokumen yang dipindai adalah diproses oleh modul perangkat lunak $O C R$. Metodologi diimplementasikan untuk mengenali urutan karakter Sebagai bagian dari pengembangan perangkat lunak perpustakaan Open $C V$ (Open Source Computer Vision) digunakan untuk melakukan pengambilan gambar dari teks, untuk melakukan pengenalan karakter. Sebagian besar alat teknologi akses dibangun untuk orang-orang dengan kebutaan dan penglihatan terbatas dibangun di atas dua blok bangunan dasar dari perangkat lunak OCR dan modul teks to Speech (TTS).

OCR adalah terjemahan gambar yang diambil dari teks di kertas ke teks yang dikodekan mesin. $O C R$ adalah proses yang menghubungkan makna simbolis dengan objek (huruf, simbol angka) dengan gambar karakter. Pengenalan Karakter Optik juga berguna untuk orang dengan gangguan penglihatan yang tidak dapat membaca dokumen teks.

Karya Ini secara luas digunakan untuk mengkonversi buku dan dokumen ke dalam file elektronik untuk digunakan dalam penyimpanan dan analisis dokumen. OCR memungkinkan untuk menerapkan pertanyaan teknis seperti terjemahan mesin, text to speech, dan penambangan teks ke halaman hasil pemindaian. Dokumen teks
Hudah, Achmad (2019)

yang sudah dikonversi diteruskan ke perangkat output. Perangkat output berupa headset yang terhubung ke raspberry pi.

Berdasarkan permasalahan diatas maka disusun rumusan masalah yang akan dibahas dalam proposal ini adalah "Bagaimana merancang dan membuat teknologi sensor kamera sebagai kacamata pengenal teks untuk tuna netra?"

Sedangkan penelitian ini bertujuan untuk mendapatkan data teks yang berbentuk cetak menjadi teks elektronik berbasis mikrokontroler Raspberry pi. Selain itu untuk membantu kaum tunanetra agar dapat mendapatkan informasi berupa teks yang dikonversi menjadi data audio

\section{Tunanetra}

Secara umum para medis mendefinisikan tunanetra sebagai orang yang memiliki ketajaman sentral 20/200 feet atau ketajaman penglihatan hanya pada jarak 6meter atau kurang, walaupun dengan menggunakan kacamata, atau daerah penglihatannya sempit sehingga jarak sudutnya tidak lebih dari 20 derajat. Sedangkan orang dengan penglihatan normal akan mampu melihat dengan jelas sampai pada jarak 60meter atau 200 kaki. (Hidayat \& Suwandi, 2013).

\section{Python}

Pyhton diciptakan oleh Guido van Rossum pertama kali di Scitchting Mathematisch Centrum (CWI) di Belanda pada awal tahun 1990-an. Bahasa python terinspirasi dari bahasa pemrograman ABC. Sampai sekarang, Guido masih menjadi penulis utama untuk python, meskipun bersifat open source sehingga ribuan orang juga berkontribusi dalam mengembangkannya. Di tahun 1995, Guido melanjutkan pembuatan python di Corporation for National Research Initiative (CNRI) di Virginia Amerika, dimana dia merilis beberapa versi dari python.

\section{Raspberry Pi Camera}

Kamera adalah alat optik untuk merekam gambar, yang dapat disimpan secara lokal, dikirmkan ke lokasi lain atau keduanya. Gambar adalah foto-foto masih individu sedangkan urutan beberapa gambar disebut video atau film. Kata kamera berasal dari camera obscura, yang berarti "ruang gelap" 
dan adalah nama latin dari perangkat asli untuk memproyeksikan gambar dari realitas eksternal ke permukaan datar. Kamera fotografi yang modern berevolusi dari kamera obscura. Fungsi kamera ini sangat mirip dengan fungsi mata manusia.

Sebuah kamera dapat bekerja dengan cahaya dari spektrum yang terlihat atau dengan bagian-bagian lain dari spektrum elektromagnetik. Sebuah perangkat optik yang menciptakan satu gambar dari suatu obyek atau adegan, dan mencatat pada sebuah sensor elektronik atau fotografi. Mekanisme rana mengontrol lamanya waktu cahaya bisa masuk kamera. Sebagian besar kamera fotografi memiliki fungsi yang memungkinkan seseorang untuk melihat adegan yang akan direkam, memungkinkan untuk bagian yang diinginkan dari tempat kejadian untuk menjadi fokus, dan mengendalikan eksposur sehingga tidak terlalu terang atau terlalu redup. Biasanya kamera menggunakan layar (LCD), memungkinkan pengguna untuk melihat adegan yang akan direkam dan pengaturan seperti kecepatan ISO, exposure, dan kecepatan rana.

\section{Speaker}

Speaker adalah perangkat keras output yang berfungsi mengeluarkan hasil pemrosesan oleh CPU berupa audio/suara. Speaker juga disebut alat bantu untuk keluaran suara yang dihasilkan oleh perangkat music, Dalam konteks komputerisasi, speaker memiliki fungsi sebagai alat untuk mengubah gelombang listrik yang mulanya dari perangkat penguat audio/suara menjadi gelombang getaran yaitu berupa suara itu sendiri. Proses dari perubahan gelombang elektromagnet menuju ke gelombang bunyi tersebut bermula dari aliran listrik yang ada pada penguat audio/suara kemudian dialirkan ke dalam kumparan. Dalam kumparan tadi terjadilah pengaruh gaya magnet pada speaker yang sesuai dengan kuat lemahnya arus listrik yang diperoleh maka getaran yang dihasilkan yaitu pada membran akan mengikuti, lalu terjadilah gelombang bunyi yang dalam keseharian dapat didengar.

\section{METODOLOGI PENELITIAN}

Dalam menentukan metode penelitian yang digunakan penulis dalam penelitian ini adalah metode waterfall yang mengarah pada hasil penelitian dengan tujuan yang ingin dicapai, dengan mengolah berbagai data dan informasi

1. Metode Perencanaan

Dalam tahap perencanaan peneliti membuat perencanaan untuk meneliti penyedia lapangan futsal pada metro futsal, bali futsal, victory futal dan penyewa lapangan futsal untuk mendapatkan informasi dan mengetahui permasalahan yang akan diteliti dengan melakukan pengumpulan data dan informasi. Pengumpulan data dan informasi pada perencanaan ini akan dikumpulkan dengan menggunakan metode validation board.

\section{Metode Pengumpulan Data}

a. Wawancara dan observasi dilakukan di tempat yayasan tunanetra, Wawancara dilakukan terhadap kaum tunanetra untuk mengetahui feedback apakah akan berguna dan dapat membantu mereka dalam kehidupan sehari-hari

b. Melakukan penyebaran kuesioner dan wawancara dengan metode validationboard pada penderita tunanetra agar mendapatkan informasi, sehingga mengetahui tingkat keberhasilan alat tersebut

c. Studi pustaka, melakukan pengumpulan informasi dari buku, teks penelitian terdahulu dan melalui internet sebagai referensi.

3. Metode Analisis dan Desain Sistem Dalam tahapan analisis, peneliti melakukan beberapa kegiatan diantaranya 
mempelajari embedded system, dan menggambarkan sistem yang sedang berjalan kedalam alat bantu analisis dan perancangan yaitu Flowchart dari yang sedang berjalan, mencari alternatif pemecahan masalah, dan pemilihan (choice) alternative pemecahan masalah yang tepat. Dalam tahapan desain sistem, peneliti memberikan gambaran tentang perancangan dari sistem yang akan dibuat untuk memberikan alternatif pemecahan masalah. Langkah-langkah yang dilakukan peneliti dalam tahapan desain sistem ini ialah membuat tujuan dari perancangan sistem, membuat gambaran umum atau deskripsi global sistem yang dirancang, merancang prosedur sistem yang diusulkan dengan membuat Flow Chart, Use Case Diagram.

4. Metode Perancangan

Pada penelitian ini,metode perencanaan aplikasi yang digunakan adalah Waterfall. Model Waterfall adalah model klasik yang bersifat sistematis, berurutan dalam membangun sistem,dimana proses pengerjaannya bertahap dan harus menunggu tahap sebelumnya selesai kemudian mengerjakan tahap selanjutnya, mulai dari analisa, design, coding, testing, penerapan dan pemeliharaan. Tahapan metodeWaterfall adalah sebagai berikut:

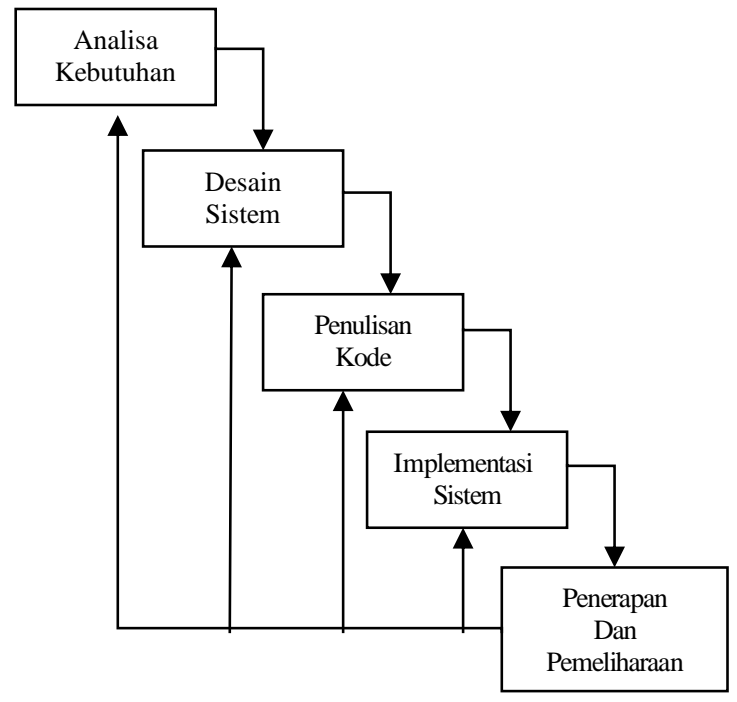

Gambar 1. Tahapan Metode Waterfall

5. Metode Pengembangan Dalam tahap pengembangan ini pemecahan masalah yang telah dirancang dan telah dibuat dalam sebuah alat berbasis embedded
Hudah, Achmad (2019)

system dan telah ditesting untuk ditemukan error atau kesalahannya yang kemudian diimplementasikan ketika sudah berhasil berjalan, akan terus dikembangkan untuk mendapatkan hasil yang semakin optimal guna untuk semakin meningkatkan kualitas alat yang telah dibuat sehingga semakin berkembang serta dapat semakin membantu tunanetra dalam mengakses informasi

\section{Instrumen Penelitian}

A. Metode Perencanaan

a. Melakukan wawancara pada kaum tunanetra untuk mendapatkan informasi dan data.

b. Melakukan wawancara untuk tunanetra guna untuk mendapatkan informasi lebih banyak mengenai kendala apa saja yang dihadapi guna mengetahui permasalahan lebih dalam serta untuk mengumpulkan data.

B. Metode Pengumpulan Data

a. Wawancara menggunakan metode validation board

b. Kuesioner menggunakan metode skala likert

C. Metode Analisis dan Desain

a. Flowchart: yang menunjukkan proses cara kerja system

b. Flowchart: untuk mempermudah dalam menentukan tahapan pembuatan alat

c. Use Case Diagram: untuk menggambarkan semua faktor yang terlibat didalam sistem.

D. Metode Perancangan

a. Perangkat Keras

1. Raspberry pi

- SoC: Broadcom BCM2837

- CPU: 4x ARM Cortex-A53, $1.2 \mathrm{GHz}$

- GPU: Broadcom VideoCore IV

- RAM: 1GB LPDDR2 (900 MHz)

- Networking: 10/100 Ethernet, 2.4GHz 802.11n wireless

- Bluetooth: Bluetooth 4.1 Classic, Bluetooth Low Energy

- Storage: microSD

- GPIO: 40-pin header, populated

- Ports: HDMI, $3.5 \mathrm{~mm}$ analogue audio-video jack, 4x USB 2.0, 
Ethernet, Camera Serial Interface (CSI), Display Serial Interface (DSI)

2. Camera Modul Camera Raspberry 8mp

3. Speaker Headphone Beats Solo HD.

b. Perangkat Lunak

- Sistem Operasi: Raspbian

- Applikasi: Python 3.5.3

c. Testing: Black Box Testing, untuk mengetahui apakah perangkat lunak berfungsi dengan benar. Selain itu, pengujian Black Box juga merupakan metode perancangan data uji yang didasarkan pada spesifikasi perangkat lunak. Data uji dibangkitkan, dieksekusi pada perangkat lunak dan kemudian keluaran dari perangkat lunak dicek apakah telah sesuai dengan yang diharapkan.

E. Metode Pengembangan

a. Meningkatkan kualitas alat dari segala masukan dan pembaharuan yang ada sehingga alat yang telah dibuat semakin memudahkan pengguna dalam mengakses informasi guna meningkatkan taraf kehidupan sehingga membantu pengguna untuk mendapatkan informasi-informasi yang terus meningkat kualitasnya yang mungkin kedepannya akan dikembangkan lebih luas lagi diberbagai yayasan tuna netra yang ada di Malang bahkan di Indonesia.

b. Terus mengembangkan dan meningkatkan kualitas alat sesuai dengan apa yang dibutuhkan oleh tunanetra sehingga pengguna alat menjadi semakin terbantu dalam mengakses informasi.

\section{HASIL DAN PEMBAHASAN Hasil Perancangan Perangkat Keras}

Setelah dilakukan perancangan terlihat bentuk fisik alat bantu baca untuk penyandang tunanetra menggunakan Raspberry Pi. Pada alat tersebut peneliti menggunakan kamera Raspberry Pi sebagai input utama pada alat, kamera berfungsi untuk melakukan graphical capture tulisan cetak pada kertas/halaman buku. Setelah dilakukan graphical capture, file akan dihasilkan sebuah file citra 60 dengan ekstensi*.jpeg. Citra yang diperoleh kemudian diolah pada proses OCR hasil proses tersebut menghasilkan file*.txt, selanjutnya akan dilakukan proses Text to Speech (TTS) untuk konversi teks kedalam ucapan/speech kemudan diperdengarkan kepada penyandang tuna netra melalui pengeras suara/speaker. Alat ini memiliki sebuah tombol kontrol untuk memulai proses pembacaan.

\section{A. Pengujian Sistem}

Pengujian sistem merupakan proses pengeksekusian perangkat keras dan perangkat lunak untuk menentukan apakah sistem tersebut cocok dan sesuai dengan yang diinginkan peneliti. Pengujian dilakukan dengan beberapa percobaan untuk melihat kemungkinan kesalahan yang terjadi dari setiap proses. Adapun pengujian yang digunakan pada penelitian ini ada metode pengujian Black Box. Pengujian perangkat dari segi spesifikasi fungsional tanpa menguji desain dan kode program. Pengujian ini dimaksudkan apakah fungsi-fungsi dan keluaran sudah berjalan sesuai dengan keinginan.

Dalam melakukan pengujian, perlu dilakukan pengujian fungsi-fungsi perbagian setelah itu dilakukan pengujian fungsi secara keseluruhan. Yang akan dilakukan pertama kali adalah melakukan pengujian fungsi masukan push button, Raspberry Pi camera, pengujian fungsi OCR, lalu pengujian fungsi TTS. Kemudian melakukan pengujian secara keseluruhan fungsi dari alat. Adapun tahapan-tahapan dalam pengujian sistem kontrol ini adalah sebagai berikut: 


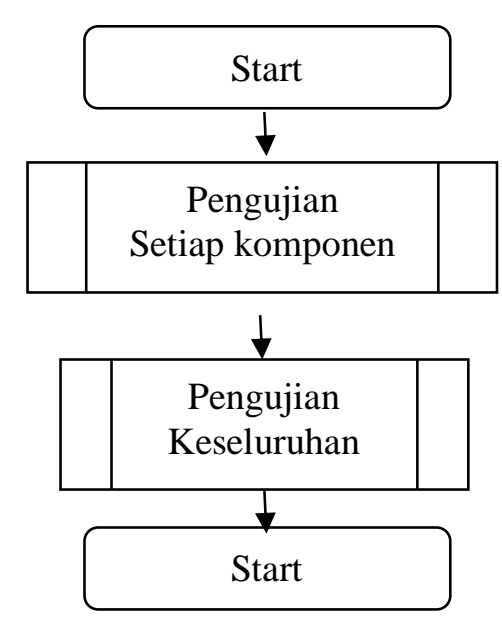

Gambar 2. Tahapan Pengujian

B. Pengujian Setiap Komponen

a. Pengujian push button

Pengujian yang dilakukan dengan menggunakan sebuah source code yang dibuat dengan nama pushbutton_test.py berikut:

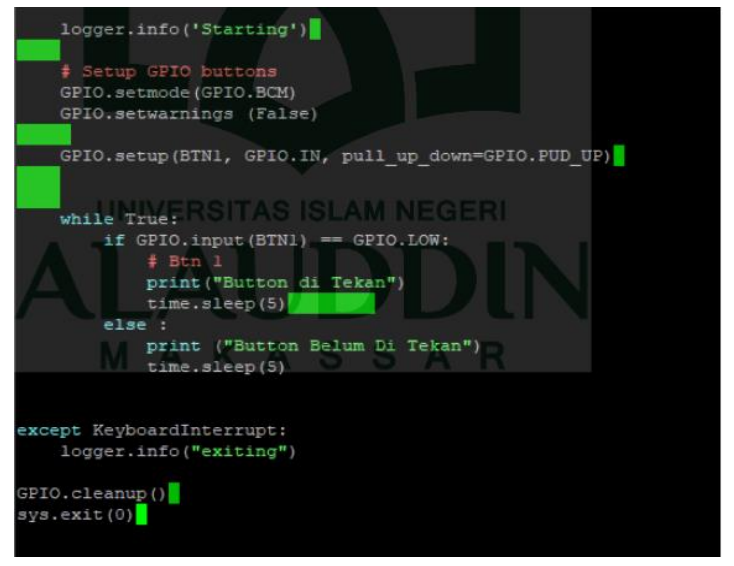

Gambar 3. Source Code Tes Fungsi Push Button

Hasil uji push button

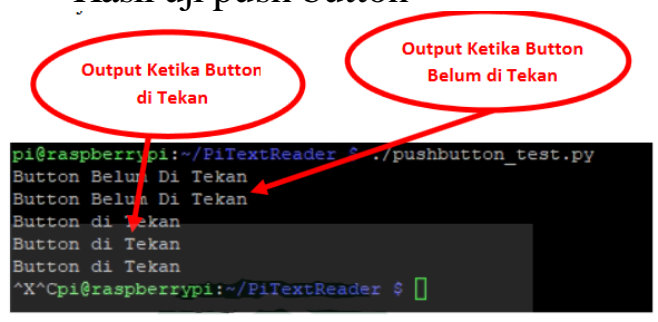

Gambar 4. Hasil Uji Fungsi Push

\section{Button}

Pada gambar 4 dapat dilihat hasil uji yang menunjukkan bahwa Push Button pada alat dapat berfungsi sebagaimana mestinya.
Hudah, Achmad (2019)

b. Pengujian Raspberry Pi Camera

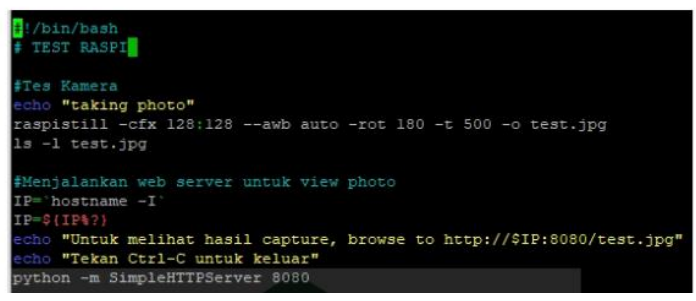

Gambar 5. Source Code Tes Fungsi Camera

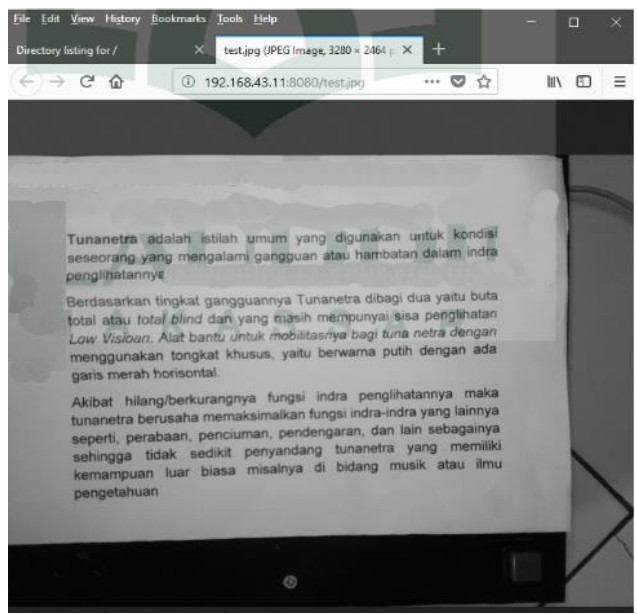

Gambar 6. Hasil Graphical Capture Melalui Kamera

Pada gambar V.9 dapat dilihat sebuah file gambar dengan nama filetest.jpg hasil pengambilan gambar melalui kamera yang dapat di akses melalui webserver dan dibuka melalui web browser.

c. Pengujian OCR

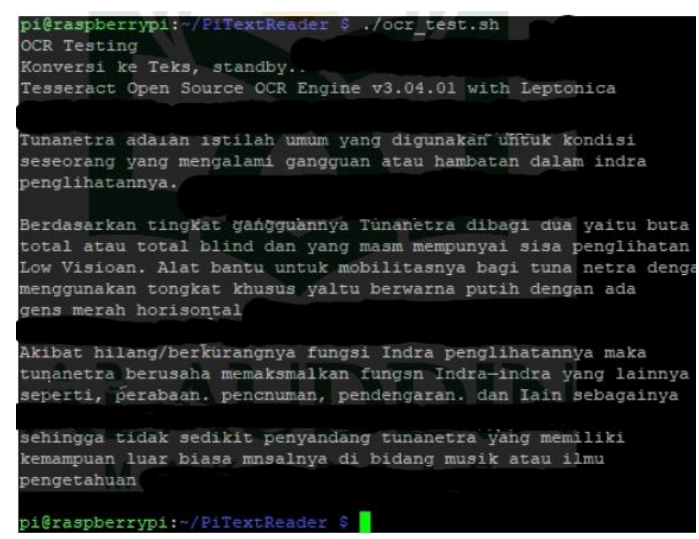

Gambar 7. Hasil Proses OCR

Dari gambar 7 dapat di lihat hasil konversi gambar dari filetest.jpg kedalam file teks test.txt. Dapat dilihat bahwa masih ada beberapa huruf yang mengalami kesalahan pembacaan, dikarenakan kemiripan model/bentuk huruf. 
d. Pengujian Text to Speech (TTS)

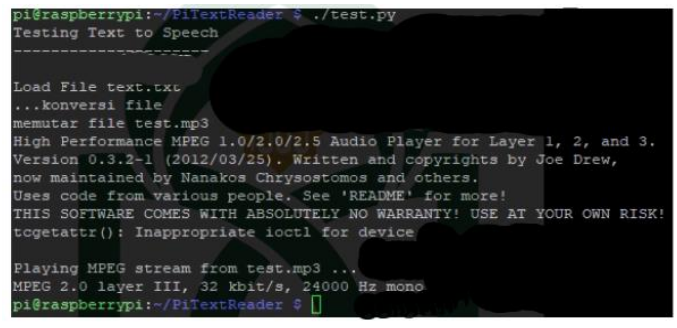

Gambar 8. Proses TTS

Dari gambar V.11dapat dilihat proses konversi file tekstest.txt menjadi speech/ucapan dalam bentuk file dengan ekstesi*.mp3 dengan nama filetest.mp3.

C. Pengujian Keseluruhan Sistem

Pengujian sistem secara keseluruhan dilakukan untuk melihat proses yang terjadi secara kesuluruhan mulai dari fungsi push button, Raspberry Pi camera, fungsi OCR dan fungsi TTS

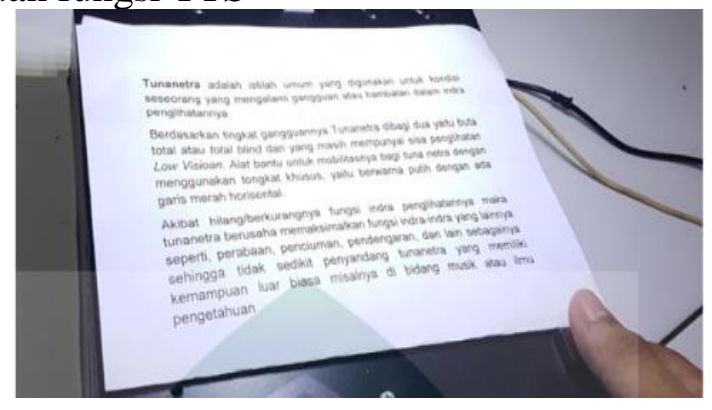

Gambar 9. Proses Menekan Push Button

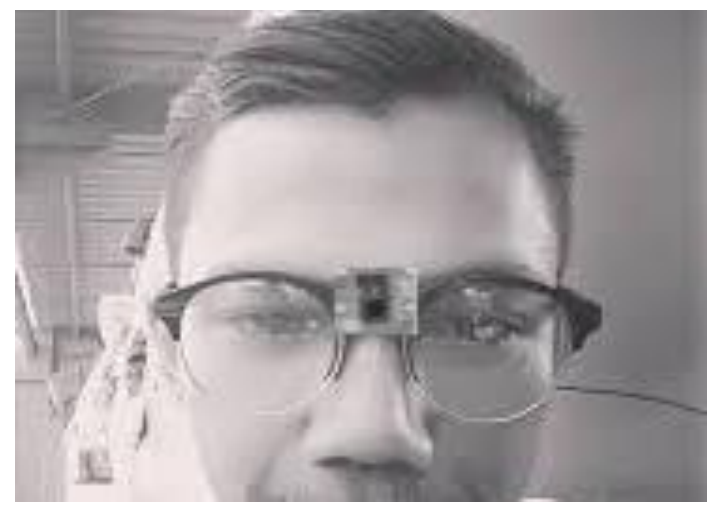

Gambar 10. Raspberry Pi Camera

Melakukan Proses Graphical Capture

Secara otomatis setelah menekan push button, Raspberry Pi Camera pada alat akan melakukan graphical capture dan menghasilkan file dengan ekstensi *jpg. Lalu file tersebut diolah dengan proses OCR untuk menghasilkan sebuah file dengan ekstensi *txt. Alat kemudian secara otomatis melalukan konversi file *.txt kedalam suara/ucapan lalu diperdengarkan melalui pengeras suara/speaker.

a. Pengujian Huruf Kapital

Pengujian pertama dilakukan dengan menggunakan tiga jenis huruf kapital dengan jenis huruf Arial, Calibridan Times New Roman dengan ukuran yang berbeda beda pula.Untuk penyajian data hasil percobaan dapat di lihat pada tabel yang tertera berikut ini :

Tabel 1. Pengujian Pembacaan Huruf Kapital

\begin{tabular}{|c|c|c|c|c|c|}
\hline \multirow{2}{*}{$\begin{array}{l}\text { Lenis } \\
\text { Huruf }\end{array}$} & \multirow{2}{*}{$\begin{array}{l}\text { Ukuran } \\
\text { Huruf }\end{array}$} & \multirow{2}{*}{$\begin{array}{l}\text { Waktu } \\
\text { Baca } \\
\text { (detik) }\end{array}$} & \multicolumn{2}{|c|}{$\begin{array}{c}\text { Pembacaan Kata } \\
\text { (PRODISISKOMASIA16) } 17 \\
\text { Huruf } \\
\end{array}$} & \multirow[t]{2}{*}{ Persentase $\%$} \\
\hline & & & $\begin{array}{c}\text { Jumlah Huruf } \\
\text { Benax }\end{array}$ & $\begin{array}{l}\text { Jumlah Huruf } \\
\text { Salah }\end{array}$ & \\
\hline Anial & 14 & 8 & 15 & 2 & 88,24 \\
\hline Arial & 15 & 8 & 15 & 1 & 94,12 \\
\hline Arial & 16 & 7 & 16 & 1 & 94,12 \\
\hline Anial & 17 & 5 & 17 & 0 & 100,00 \\
\hline Calibri & 14 & 8 & 14 & 3 & 82,35 \\
\hline Calibri & 15 & 7 & 15 & 2 & 88,24 \\
\hline Calibri & 16 & 7 & 17 & 0 & 100,00 \\
\hline Calibri & 17 & 5 & 17 & 0 & 100,00 \\
\hline $\begin{array}{l}\text { Times } \\
\text { New } \\
\text { Roman }\end{array}$ & 14 & 9 & 13 & 4 & 76.47 \\
\hline $\begin{array}{l}\text { Times } \\
\text { New } \\
\text { Roman }\end{array}$ & 15 & 8 & 14 & 3 & 82,35 \\
\hline $\begin{array}{l}\text { Times } \\
\text { New } \\
\text { Roman }\end{array}$ & 16 & 7 & 15 & 2 & 88,24 \\
\hline $\begin{array}{l}\text { Times } \\
\text { New } \\
\text { Roman }\end{array}$ & 17 & 6 & 15 & 2 & 88,24 \\
\hline & & & a-Rata & & 90,20 \\
\hline
\end{tabular}

Dari tabel 1dapat dilihat hasil pengujian dengan menggunakan beberapa jenis huruf yang berbeda. Yaitu Arial, Calibri dan Times New Roman. Dengan konfigurasi ukuran huruf yang berbeda-beda pula. Peneliti kali ini mengambil rentang ukuran huruf dari 14-17. Rentang nilai ini di ambil disesuaikan dengan pengaturan jarak Raspberry Pi Camera dari kertas/halaman buku. Dari tabel di atas menunjukkan bahwa alat dapat berfungsi dengan nilai rata-rata $90.20 \%$. Untuk sajian data dalam bentuk grafik dapat dilihat sebagai berikut 
Persentasi Benar (\%)

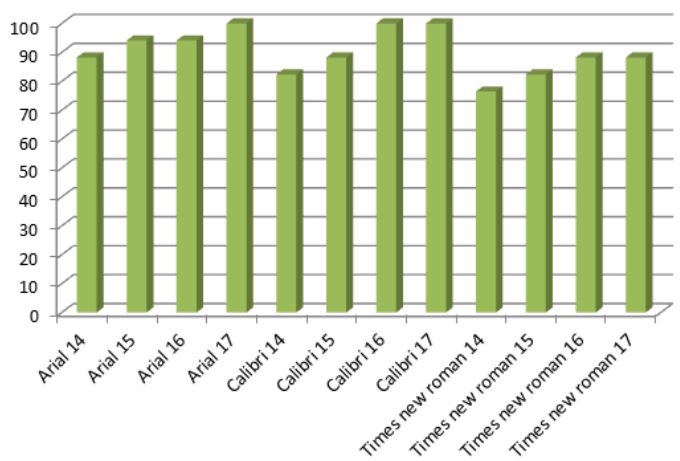

Gambar 11. Grafik Hasil Pengujian Huruf Kapital

$88 \%+94 \%+94 \%+100 \%+82,4 \%+88 \%+100 \%+100 \%+76,5 \%+82 \%+88 \%+88 \%$

$=90,20 \%$

Rata-rata(mean):

Rata-rata $(\mathrm{X})=\frac{\sum X n}{n}$

$\mathrm{X}=\frac{1.082}{12}$

$X=90,20$

Hasil di atas menunjukkan bahwa pengujian alat ini dengan niai $90,20 \%$ memenuhi standar keakuratan fungsi alat.

b. Pengujian Huruf Kecil

Pengujian pertama dilakukan dengan menggunakan tiga (3) jenis huruf kecil dengan jenis huruf Arial, Calibri dan Times New Roman dengan ukuran yang berbeda beda pula. Untuk penyajian data hasil percobaan dapat dilihat pada tabel yang tertera berikut ini:

Tabel 2. Pengujian Pembacaan Huruf kecil

\begin{tabular}{|c|c|c|c|c|c|}
\hline \multirow{2}{*}{$\begin{array}{l}\text { Jenis } \\
\text { Huruf }\end{array}$} & \multirow{2}{*}{$\begin{array}{l}\text { Ukuran } \\
\text { Huruf }\end{array}$} & \multirow{2}{*}{$\begin{array}{l}\text { Waktu } \\
\text { Baca } \\
\text { (detik) }\end{array}$} & \multicolumn{2}{|c|}{$\begin{array}{c}\text { Pembacaan Kata } \\
\text { (PRODISISKOMASIA16) } \\
17 \text { Huruf } \\
\end{array}$} & \multirow{2}{*}{$\begin{array}{c}\text { Persentase } \\
\%\end{array}$} \\
\hline & & & $\begin{array}{c}\text { Jumlah } \\
\text { Huruf Benar }\end{array}$ & $\begin{array}{c}\text { Jumlah } \\
\text { Huruf Salah }\end{array}$ & \\
\hline Arial & 14 & 8 & 14 & 3 & 88,35 \\
\hline Arial & 15 & 8 & 15 & 2 & 88,24 \\
\hline Arial & 16 & 7 & 16 & 1 & 94,12 \\
\hline Arial & 17 & 6 & 17 & 0 & 100,00 \\
\hline Calibri & 14 & 8 & 14 & 3 & 82,35 \\
\hline Calibri & 15 & 7 & 14 & 3 & 88,35 \\
\hline Calibri & 16 & 7 & 16 & 1 & 94,12 \\
\hline Calibri & 17 & 6 & 17 & 0 & 100,00 \\
\hline $\begin{array}{l}\text { Times } \\
\text { New } \\
\text { Roman }\end{array}$ & 14 & 9 & 13 & 4 & 76,47 \\
\hline $\begin{array}{l}\text { Times } \\
\text { New } \\
\text { Roman }\end{array}$ & 15 & 13 & 13 & 4 & 76,47 \\
\hline $\begin{array}{l}\text { Times } \\
\text { New } \\
\text { Roman }\end{array}$ & 16 & 15 & 15 & 2 & 88,24 \\
\hline $\begin{array}{l}\text { Times } \\
\text { New } \\
\text { Roman }\end{array}$ & 17 & 15 & 15 & 2 & 88,24 \\
\hline \multicolumn{5}{|c|}{ Rata-Rata } & 87,75 \\
\hline
\end{tabular}

Dari tabel 2 dapat dilihat hasil pengujian dengan menggunakan beberapa jenis huruf yang berbeda.
Hudah, Achmad (2019)

Dari tabel di atas menunjukkan bahwa alat dapat berfungsi dengan nilai ratarata $87.75 \%$. Untuk sajian data dalam bentukgrafik dapat dilihat sebagai berikut:

Persentasi Benar (\%)

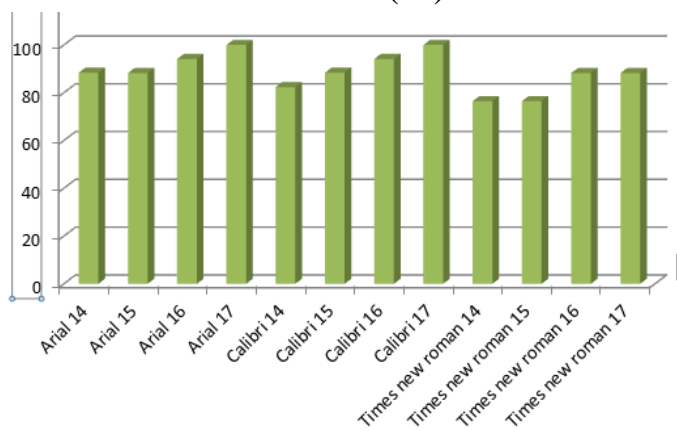

Gambar 12. Grafik Hasil Pengujian Huruf Kecil

$82 \%+88 \%+94 \%+100 \%+82 \%+82 \%+94 \%+100 \%+76,5 \%+76,5 \%+88 \%+88 \%=87,75 \%$

Rata-rata(mean):

Rata-rata $(\mathrm{X})=\frac{\sum \mathrm{Xn}}{n}$

$$
X=\frac{1052}{12}=87,75
$$

Rata-rata(mean):

Rata-rata $(\mathrm{X}) \quad=\sum \quad \mathrm{Xnn}(\mathrm{X})$ $=1.05212(\mathrm{X})=87.75$

Hasil di atas menunjukkan bahwa pengujian alat ini menggunakan huruf kecil dengan niai $87,75 \%$ memenuhi standar keakuratan fungsi alat

\section{KESIMPULAN}

Adapun kesimpulan yang didapatkan dalam penelitian ini adalah sebagai berikut:

- Alat ini berfungsi sebagai alat bantu baca untuk penyandang tunanetra dalam membaca tulisan cetak dari sebuah kertas/halaman buku. Alat ini berhasil dibangun dengan Raspberry PI sebagai mikrokontroller, dengan trigger dari Push Button sebuah Raspberry Pi Camera akan melakukan graphical capture dan menghasilkan sebuah file gambar yang secara otomatisakan diolah dengan proses OCR dan diubah kedalam ucapan dengan proses TTS. Hasil dari rentetan proses ini menghasilkan sebuah file mp3 untuk diperdengarkan ke penyandang tuna netra sehingga penyandang tuna netra dapat membaca secara tidak langsung dari tulisan cetak dari sebuah kertas/halaman buku 
- Alat ini mempunyai beberapa keunggulan yakni penyandang tuna netra dapat menambah khasanah keilmuan tidak lagi mengandalkan buku cetak braille tapi juga buku konvensional yang dibaca manusia normal pada umumnya. Selain itu alat ini juga memiliki portabilitas yang tinggi, alat dapat dengan mudah dipindahkan dan mudah dalam penggunaannya.

Adapun saran-saran yang dapat disampaikan dalam penelitian ini adalah sebagai berikut:

- Untuk hasil maksimum sebaiknya gunakan kamera dengan resolusi yang lebih tinggi dari spesifikasi yang digunakan oleh penulis

- Pada alat ini untuk mengetahui penempatan kertas terbalik atau tidak sesuai dengan posisi yang semestinya masih mengandalkan proses manual dan mengedepankan experience dari pengguna agar terbiasa menggunakan alat ini. Untuk kenyamanan penggunaan, perlu penambahan fitur pada alat yang dapat mendeteksi secara otomatis posisi kertas yang terbalik atau dalam posisi yang tidak semestinya

\section{REFERENSI}

[1] Fadlisyah.2007.Computer Vision dan Pengolahan Citra. Penerbit Andi.Yogyakarta

[2] Ichsan. 2010. Implementasi Teknik Kompresi Gambar Dengan Algoritma Partitioning In Hierarchical Trees Pada Perangkat Bergerak, Teknik Elektro. Universitas SUMUT. Medan

[3] Usman, Ahmad. 2005. Pengolahan Citra Digital \& $\quad$ Teknik Pemrogramannya. Penerbit Graha Ilmu. Yogyakarta 